\title{
PENERAPAN SOMATIC AUDITORY VISUALIZATION INTELLECTUALLY (SAVI) MENGGUNAKAN CD INTEAKTIF TERHADAP HASIL BELAJAR
}

\author{
Vivi Putri Utami ${ }^{1)}$, Miterianifa ${ }^{2)}$. \\ ${ }^{1}$ Fakultas Tarbiyah dan Keguruan Universitas Islam Negeri Sultan Syarif Kasim Riau Pekanbaru \\ Email Utami_viviputri@yahoo.com \\ ${ }^{2}$ Pendidikan Kimia Fakultas Tarbiyah dan Keguruan Universitas Islam Negeri Sultan Syarif Kasim Riau \\ Pekanbaru
}

\begin{abstract}
This research was instigated by the low achievement on Atomic Structure material of $X$ grade students at State Agricultural Integrated Vocational High School in the Academic Year of 2015/2016. This research was an experiment. This research aimed at knowing how the effect of using Somatic Auditory Visualization Intellectually (SAVI) learning model with Interactive CD about Atomic Structure toward students' Achievements was. The research design was using pretest and posttest. The sample technique of this research was Simple Random Sampling. X ATPH 1 was the experimental group and X ATPH 2 was the control group. The techniques of collecting data were by measuring the homogeneity test as the preliminary data in the previous material (introduction to chemistry), Interview, documentation, observation, pretest and posttest as the final data. The data were analyzed by using T-test formula. The final calculation state that $t_{\text {observed }} 2,401$ was higher than $t_{\text {table }} 2,00$ at $5 \%$ significant level. It revealed that $H_{0}$ was rejected and $H_{a}$ was accepted. The research findings showed that (1) Somatic Auditory Visualization Intellectually (SAVI) Learning Model with Interactive CD about Atomic Structure Influenced Students' Achievement, (2) the influence of using Somatic Auditory Visualization Intellectually (SAVI) Learning Model with Interactive CD about Atomic Structure Influenced Students' Achievement was $7,7 \%$.
\end{abstract}

Keywords: Cooperative Learning Model, Achievements, Somatic Auditory Visualization Intellectually (SAVI), Interactive CD, Atomic Structure.

sifat pribadi agar proses itu dapat berlangsung dengan efektif dan efisien.

\section{PENDAHULUAN}

Pendidikan merupakan kebutuhan pokok bagi manusia, karena manusia disaat dilahirkan tidak mengetahui sesuatu apapun. Dengan adanya pendidikan manusia akan mempunyai banyak ketrampilan dan kepribadian. Salah satu pendidikan yang kita dapatkan adalah pendidikan di sekolah yaitu melalui proses belajar atau aktivitas belajar. Di dalam Proses belajar-mengajar, guru sebagai pengajar dan siswa sebagai subjek belajar, dituntut adanya profil kualifikasi tertentu dalam hal pengetahuan, kemampuan, sikap dan tata nilai serta sifat-
Untuk itu, orang kemudian mengembangkan berbagai pengetahuan, misalnya psikologi pendidikan, metode mengajar, pengelolaan pengajaran, dan ilmu-ilmu lain yang dapat menunjang proses belajar-mengajar itu. Guru mempunyai tugas untuk mendorong, membimbing, dan memberi fasilitas belajar bagi siswa unutuk mencapai tujuan. Guru mempunyai tanggung jawab untuk melihat segala sesuatu yang terjadi dalam kelas untuk membantu proses perkembangan siswa

Kimia merupakan salah satu bagian dari Ilmu Pengetahuan Alam (IPA) yang memiliki dimensi proses dan dimensi hasil 
yang terkait satu dengan yang lainnya. Konsep atau teori dalam materi kimia cenderung bersifat abstrak sehingga tidak mudah untuk dipahami, banyak siswa kurang berminat terhadap mata pelajaran kimia. Untuk mempelajari materi kimia diperlukan aktivitas belajar yang baik.

Dalam pembelajaran kimia, siswa tidak cukup hanya dengan mendengarkan penjelasan guru, tetapi juga dituntut berpartisipasi aktif dan mempraktikkan sendiri untuk mendapatkan konsep materi melalui pengalaman langsung. Pembelajaran dengan pengalaman langsung akan memberikan kebermaknaan belajar bagi siswa.

Pengalaman langsung dalam proses belajar mengajar dapat terjadi melalui percobaan, diskusi, penelitian, proyek pelayanan, dan sebagainya. Agar proses belajar menjadi efektif, perlulah adanya usaha menciptakan pengalaman langsung tersebut. Cara berinteraksi atau metodemetode yang dapat digunakan misalnya dengan diskusi, demonstrasi, sosiodrama, role playing. Kaitan antara pengalaman langsung atau real experience dengan media pembelajaran merupakan suatu cara atau proses pembelajaran yang dilakukan untuk mendapatkan kejelasan dalam suatu objek atau keterangan secara lebih kongkrit dan tepat, serta menghindari terjadinya adanya perbedaan dan kesalahan-kesalahan persepsi dengan cara melihat suatu objek dengan keadaan sesungguhnya. Hal ini tidak terlepas dari penggunaan alat peraga dan media pembelajaran yang tepat dan memadai. Sehingga proses pembelajaran menjadi lebih menarik dan menyenangkan. Kualitas pengalaman belajar adalah hal yang penting. Saat ini peningkatan kualitas situasi kegiatan belajar mengajar merupakan perkembangan positif dalam pendidikan yang lebih berkualitas.

Dalam implementasi kurikulum 2013 menuntut kerjasama yang optimal di antara para guru, sehingga memerlukan pembelajaran berbentuk tim, dan menuntut kerjasama yang kompak di antara para anggota tim. Kerjasama antara para guru sangat penting dalam proses pendidikan. Dalam pembelajaran kelompok, siswa mendapatkan kesempatan seluas-luasnya untuk bekerjasama dalam menyelesaikan tugas-tugas yang terstruktur. Para siswa diharapkan memiliki sikap saling ketergantungan yang positif, adanya tanggung jawab perorangan, komunikasi antar anggota, serta evaluasi proses kelompok.

Menurut Permendikbud No. 81 A Tahun 2013 Lampiran IV, proses pembelajaran Saintifik terdiri atas Lima Pengalaman Belajar Pokok, Yaitu: Mengamati, menanya, menalar, mengasosiasi dan mengkomunikasikan. Media sangat diperlukan perananya dalam pembelajaran saintifik, Terutama untuk kegiatan pengamatan dan mengkomunikasikan di dalam menalar (mengumpulkan data). Salah satu media atau sarana yang dapat diterapakan dalam kurikulum 2013 adalah LCD atau Komputer. Dengan bantuan LCD, siswa mengamati tayangan tertentu sesuai dengan KD yang dikembangkan guru.

Berdasarkan observasi dan wawancara dengan guru kimia kelas $\mathrm{X}$ di Sekolah Menengah Kejuruan (SMK) Negeri Pertanian Terpadu Pekanbaru, diungkapkan permasalahan yang dialami dalam pembelajaran kimia adalah dikarenakan model pembelajaran yang digunakan oleh guru masih membuat siswa kurang aktif dalam belajar, dalam berdiskusi siswa kurang terbiasa mengutarakan argumennya. Model yang digunakan hanya membuat auditori siswa saja yang aktif. Padahal siswa memiliki gaya belajar yang berbeda-beda dalam memahami pembelajaran. Pada gaya belajar auditory, siswa hanya bersifat sebagai audiences hanya menerima saja apa yang disampaikan guru. Ketika disuruh memecahkan sendiri permasalahan yang diberikan oleh guru banyak siswa yang tidak mengerti dan mendapatkan nilai di bawah KKM, siswa yang mampu melewati KKM sebesar 50\% dimana KKM (Kriteria Ketuntasan Minmum) pada materi struktur atom kelas $\mathrm{X}=75$. Pada materi struktur 
atom hanya 51,04\% siswa yang lulus dari 6 kelas.

Hal ini berdasarkan data dari nilai ulangan harian siswa pada materi struktur atom yang disajikan dalam tabel berikut:

Tabel 1. Data Rata-Rata Nilai Ulangan Harian Siswa Tahun Ajaran 2015/2016

\begin{tabular}{|c|c|c|c|c|c|}
\hline $\begin{array}{l}\mathrm{N} \\
\mathrm{o}\end{array}$ & $\begin{array}{l}\text { Nama } \\
\text { Kelas }\end{array}$ & $\begin{array}{c}\text { Jumla } \\
\text { h } \\
\text { Siswa }\end{array}$ & $\begin{array}{c}\text { Jumla } \\
\text { h } \\
\text { siswa } \\
\text { di } \\
\text { atas } \\
\text { KKM }\end{array}$ & $\begin{array}{c}\text { Jumla } \\
\text { h } \\
\text { siswa } \\
\text { di } \\
\text { bawa } \\
\text { h } \\
\text { KKM }\end{array}$ & $\begin{array}{c}\% \\
\text { siswa } \\
\text { di } \\
\text { bawah } \\
\text { KKM }\end{array}$ \\
\hline 1 & ATP1 & 34 & 17 & 17 & $50 \%$ \\
\hline 2 & APKJ & 33 & 16 & 17 & $\begin{array}{l}51,51 \\
\%\end{array}$ \\
\hline 3 & $\begin{array}{l}\text { ATPH } \\
1\end{array}$ & 33 & 16 & 17 & $\begin{array}{l}51,51 \\
\%\end{array}$ \\
\hline 4 & THP1 & 28 & 14 & 15 & $\begin{array}{l}51,72 \\
\%\end{array}$ \\
\hline 5 & APT & 33 & 17 & 16 & $\begin{array}{l}48,48 \\
\%\end{array}$ \\
\hline 6 & MP & 31 & 15 & 16 & $47 \%$ \\
\hline
\end{tabular}

\%keseluruhan $=\frac{\text { Jumlah rata-rata keseluruhan }}{\text { jumbat }}$

$$
\begin{aligned}
& =\frac{98}{192} \times 100 \% \\
& =51.04 \%
\end{aligned}
$$

Oleh karena itu, perlu dicari solusi agar pembelajaran yang dilaksanakan lebih menarik dan menyenangkan, serta tercipta pembelajaran yang dapat memaksimalkan keaktifan siswa baik aktif tubuh, indra, intelektual, maupun emosional dalam mengkonstruksi pengetahuan yang mereka dapatkan. Untuk melibatkan alat indra dan kelima alat indra dan emosi dalam proses belajar yang merupakan cara belajar secara alami yang dikenal dengan model SAVI, yaitu Somatic, Auditory, Visu-alization, and Intellectualy.

Model pembelajaran SAVI, dalam prosesnya siswa dikondisikan untuk belajar menggunakan seluruh tubuh dan seluruh pikiran secara verbal, nonverbal, rasional, emosional, dan fisik secara bersamaan. Model pembelajaran SAVI sangat memperhatikan kegembiraan dalam belajar. Kegembiraan ini berarti bangkitnya minat siswa, adanya keterlibatan penuh, dan terciptanya makna, pemahaman, dan nilai yang membahagiakan pada diri siswa. Dengan adanya kegembiraan inilah perhatian dan motivasi siswa dalam mengikuti pembelajaran akan meningkat. Kualitas perhatian dan motivasi individu terhadap belajar sangat mempengaruhi terhadap kualitas proses dan hasil belajarnya. Model pembelajaran Somatic, Auditory, Visualization, and Intellectualy (SAVI) merupakan kerangka prosedur pelaksanaan pembelajaran yang menyenangkan dan menarik dengan memaksimalkan gerak tubuh, fungsi indra, intelektual, dan emosi dalam pemerolehan konsep materi serta mementingkan kegembiraan dalam belajar. Sehingga akan meningkatkan hasil belajar siswa.

\section{METODE PENELITIAN}

Penelitian ini merupakan penelitian quasy eksperimen. Penelitian ini dilakukan pada semester ganjil tahun ajaran 2016/2017 bulan Juli-Agustus 2016 di SMK Negeri Pertanian Terpadu Pekanbaru Provinsi Riau. Populasi dalam penelitian ini adalah siswa kelas X SMK Negeri Pertanian Terpadu yang terdiri 3 kelas yaitu: X ATPH1, X ATPH2, X APPHP1, dengan jumlah siswa sebanyak 106 orang. Teknik pengambilan sampel yang digunakan adalah menggunakan simple random sampling yang sebelumnya telah dilakukan uji homogenitas pada semua kelas. Dimana dalam penelitian ini diambil kelas X ATPH1 sebagai kelas eksperimen dan kelas X ATPH2 sebagai kelas kontrol. Teknik pengumpulan data pada penelitian ini adalah dengan melakukan uji homogenitas sebagai data awal pada materi sebelumnya yaitu pengenalan kimia, wawancara, dokumentasi, observasi, pretest, dan posttest sebagai data akhir. Teknik analisis data yang dilakukam ada dua, pertama teknik analisis soal yaitu uji validitas.

Uji validitas soal menggunakan rumus:

$$
\mathrm{r}_{\mathrm{pbi}}=\frac{\mathrm{M}_{\mathrm{p}}-\mathrm{M}_{\mathrm{t}}}{\mathrm{SD}_{\mathrm{t}}} \sqrt{\frac{\mathrm{p}}{\mathrm{q}}}
$$


Pada uji reliabilitas soal digunakan $r_{\text {ganjil-genap. Untuk mencari reliabilitas seluruh }}$ tes digunakan Spearman Brown dengan rumus:

$$
\mathrm{r}_{11}=\frac{2 \times r x y}{1+r x y}
$$

Uji tingkat kesukaran soal menggunakan rumus:

$$
P=\frac{B}{J S}
$$

Selanjutnya uji daya beda soal digunakan rumus:

$$
D=\frac{B_{A}}{J_{A}}-\frac{B_{B}}{J_{B}}=P_{A}-p_{B} .
$$

Yang kedua analisis data penelitian yaitu analisis data awal (uji homogenitas). Pengujian homogenitas varians menggunakan uji barlet, Homogenitas varians diuji dengan menggunakan rumus:

$$
\mathrm{X}^{2}=(\mathrm{In} 10)\left\{\mathrm{B}-\sum\left(\mathrm{n}_{\mathrm{i}}-1\right) \log \mathrm{Si}^{2}\right.
$$

Setelah $\chi_{\text {hitung }}^{2}$ didapatkan maka bandingkan $\chi_{\text {hitung }}^{2}$ dengan $\chi_{\text {tabel }}^{2}$ untuk $\alpha=$ 0,05 dan derajat kebebasan $(\mathrm{dk})=\mathrm{k}-1$, dengan kriteria pengujian sebagai berikut ${ }^{1}$

Jika $\chi_{\text {hitung }}^{2} \geq \chi_{\text {tabel }}^{2}$, tidak homogen

Jika $\chi_{\text {hitung }}^{2} \leq \chi_{\text {tabel }}^{2}$, homogeny

Kemudian setelah dilakukan pengujian, didapatkan kelas homogen, maka peneliti mengambil 2 kelas secara acak dengan teknik random sampling sebagai kelas eksperimen dan kelas kontrol

Selanjutnya dilakukan uji normalitas. Untuk menguji normalitasnya dapat menggunakan Chi kuadrat, maka rumus yang digunakan adalah:

$$
\mathrm{X} 2=\frac{\sum(f o-f h) 2}{\sum f h}
$$

Kriteria pengujian: normal

Jika $\mathrm{X}_{2 \text { Hitung }}<\mathrm{X}_{2}$ Tabel distribusi data

Jika $\quad \mathrm{X}_{2 \text { Hitung }}>\mathrm{X}_{2 \text { Tabel }}$ distribusi data tidak normal

Dan yang terakhir adalah analisis data akhir (uji hipotesis) dengan penentuan nilai pengaruh $\left(\mathrm{r}^{2}\right)$. Uji t yang digunakan adalah

${ }^{1}$ Riduwan, Dasar-Dasar Statistik, (Bandung, Alfabeta, 2010), hlm. 185. uji t satu pihak (1- $\alpha)$. Dengak kriteria pengujian : hipotesis diterima apabila $t_{\text {hitung }}>$ $\mathrm{t}_{\text {tabel }}$ dengan derajat kebebasan $\mathrm{dk}=\mathrm{n}_{1}+\mathrm{n}_{2}-2$ dan taraf nyatanya $\alpha=0,05$

Ho = tidak terjadi peningkatan hasil belajar

$\mathrm{Ha}=$ terjadi peningkatan hasil belajar

$t_{\text {hitung }}>t_{\text {tabel }}$ berarti Ho ditolak

$\mathrm{t}_{\text {hitung }}<\mathrm{t}_{\text {tabel }}$ berarti Ha diterima.

Pengujian dilakukan rumus dengan polled varians.

$t$

$$
=\frac{\bar{X} 1-\bar{X} 2}{\sqrt{\frac{\left(n_{1}-1\right) \mathbf{s}_{1}^{2}+\left(n_{2}-1\right) \mathbf{s}_{2}^{2}}{n_{1}+n_{2}-2}\left(\frac{1}{n_{x}}+\frac{1}{n_{y}}\right)}}(7)
$$

Untuk menentukan besarnya pengaruh dari perlakuan digunakan rumus :

$$
r^{2}=\frac{t^{2}}{t^{2}+n-2}
$$

Sedangkan untuk menentukan persentase peningkatan (koefisien pengaruh) dari perlakuan digunakan rumus :

$$
\mathrm{Kp}=\mathrm{r}^{2} \times 100 \%
$$

\section{HASIL DAN PEMBAHASAN}

Dalam analisis soal yang pertama dilakukan adalah uji validitas soal, yaitu viditas isi dan validitas empirik. Pada validitas isi didapatkan 30 soal yang sesuai indikator, yang disajikan pada tabel berikut:

Tabel 2. Rangkuman Uji Validitas isi

\begin{tabular}{clc}
\hline Kriteria & \multicolumn{1}{c}{ Nomor Soal } & Jumlah \\
\hline Valid & $1,2,3,4,5,6,7,8$, & 30 \\
& $9,10,11,12,13$, & \\
& $14,15,16,17,18$, & \\
& $19,20,21,22,23$, & \\
& $24,25,26,27,28$, & \\
& 29,30 & 30 \\
Jumlah & & \\
\hline
\end{tabular}

Pada analisis uji validitas emprik menggunakan rumus teknik product moment. Apabila Validitas $t_{\text {hitung }}>t_{\text {tabel }}$ maka soal dikatakan valid dan jika $t_{\text {hitung }}<t_{\text {tabel }}$ maka soal dikatakan tidak valid. Hasil dari uji validitas ini didapatkan $t_{\text {hitung }}>t_{\text {tabel }}$ 
sehingga soal dinyatakan valid sebanyak 27 soal yang sesuai dengan kriteria.

Selanjutnya dilakukan uji reliabilitas soal. Berdasarkan hasil analisis uji coba soal yang telah dilakukan dengan menggunakan rumus pearson product moment diperoleh realibilitas tes sebesar 0,80 dengan kriteria sangat tinggi.

Selanjutnya dilakukan analisis tingkat kesukaran soal. Pengujian tingkat kesukaran soal sangat diperlukan dalam tes hasil belajar, hal ini bertujuan untuk mengetahui soal tersebut termasuk dalam soal yang memiliki kriteria sangat sukar, sukar, sedang, mudah atau sangat mudah. Sehingga peneliti dapat menentukan soal yang layak digunakan dalam penelitian ini. Dari hasil analisis uji coba 20 butir soal, pada pokok bahasan struktur atom, diperoleh $30 \%$ soal mudah, $40 \%$ soal sedang, dan $30 \%$ soal sukar.

Selanjutnya Pengujian daya pembeda soal, dimana bertujuan untuk mengetahui soal yang memiliki kriteria sangat jelek hingga soal yang memiliki daya pembeda sangat baik. Dari hasil analisis uji daya pembeda untuk 20 soal yang diujikan, diperoleh jumlah soal $30 \%$ soal dengan kriteria cukup, $60 \%$ soal dengan kriteria baik dan $10 \%$ soal dengan kriteria baik sekali.

Setelah dilakukan anlisis terhadap soal selanjutnyadilakukan analisis data penelitian. Dalam penelitian ini dibutuhkan dua sampel yang memiliki kemampuan homogen sehingga dilakukan dengan Analisis uji homogenitas diuji dengan metode Bartlet. Dimana hasilnya dirangkum pada tabel berikut:

Tabel 4. Rangkuman Hasil Analisis Data Uji Homogenitas Awal

\begin{tabular}{llllll}
\hline Kelas & & $\sum \mathrm{X}$ & $\overline{\mathrm{X}}$ & $\mathrm{F}$ & $\mathrm{F}$ \\
& $\mathrm{N}$ & & & hitung & \begin{tabular}{l} 
table \\
\hline Eksperime
\end{tabular} \\
$\mathrm{n}$ & 2140 & 2190 & 1,16 & 1,8 \\
Kontrol & 5 & & & 2 & 0 \\
& 3 & 62,9 & 59,1 & & \\
& 6 & 4 & 9 & & \\
\hline
\end{tabular}

Setelah dilakukan uji homogenitas dan didapatkan kelas eksperimen dan kelas kontrol dilakukan tes awal yaitu disebut dengan pretest. Berdasarkan nilai pretest di dapatkan perbandingan nilai rata-rata pretest kelas eksperimen dan kelas kontrol disajikan dalam grafik di bawah ini:

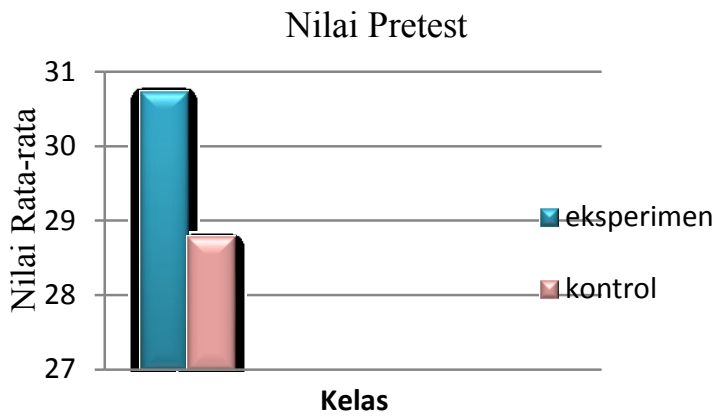

Gambar 3. Diagram perbandingan nilai ratarata pretest kelas kontrol dan eksperimen

Dapat dilihat dari nilai rata-rata pretest bahwa perbandingan presentasinya tidak terlalu jauh, karena siswa di kelas kontrol dengan siswa di kelas eksperimen samasama belum mempelajari materi dalam soal. Namun, secara keseluruhan menunjukkan bahwa hasil nilai rata-rata pretest kelas eksperimen lebih lebih tinggi dibandingkan kelas kontrol.

Pada tahap selanjutnya setelah dilakukan pretest maka dilakukan tahap pembelajaran yang mana untuk kelas eksperimen diterapkan pembelajaran saintific dengan model pembelajaran SAVI (Somatic Auditory Visualization Intelectually) dilengkapi media CD interaktif struktur atom dan kelas kontrol diterapakn model pembelajaran saintific dengan materi pemelajaran struktur atom.

Dalam proses pembelajaran juga terlihat perbedaan nilai rata-rata nilai LKS dan evaluasi belajar siswa. Dimana nilai rata-rata LKS disajikan pada grafik berikut: 
Nilai LKS

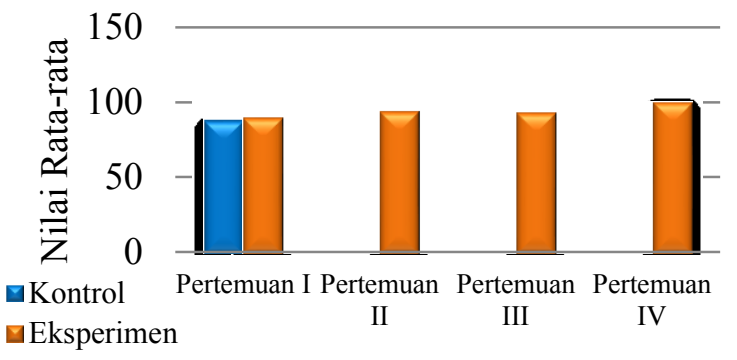

Gambar 4. Diagram perbandingan rata-rata nilai LKS kelas eksperimen dan kontrol

Dari grafik di atas dapat dilihat nilai rata-rata keseluruhan nilai LKS siswa kelas eksperimen lebih tinggi dari kelas kontrol.

Sedangkan grafik nilai rata-rata evaluasi antara kelas eksperimen dan kontrol disajikan dalam grafik di bawah ini:

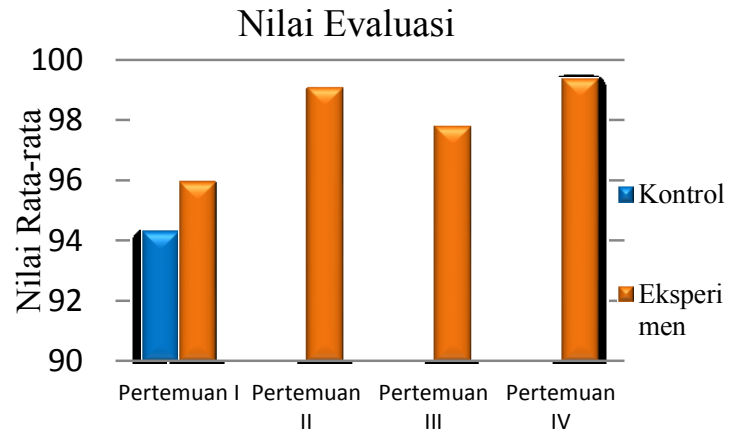

Gambar 5. Diagram perbandingan nilai evaluasi kelas kontrol dan eksperimen

Dari grafik di atas juga dapat dilihat nilai rata-rata keseluruhan nilai evaluasi siswa kelas eksperimen lebih tinggi dari kelas kontrol.

Setelah kedua kelas mempelajari kedua materi tersebut kemudian diberikan tes posttest untuk mengetahui nilai rata-rata dari kedua kelas. Perbandingan nilai ratarata posttest dapat dilihat pada grafik di bawah ini:

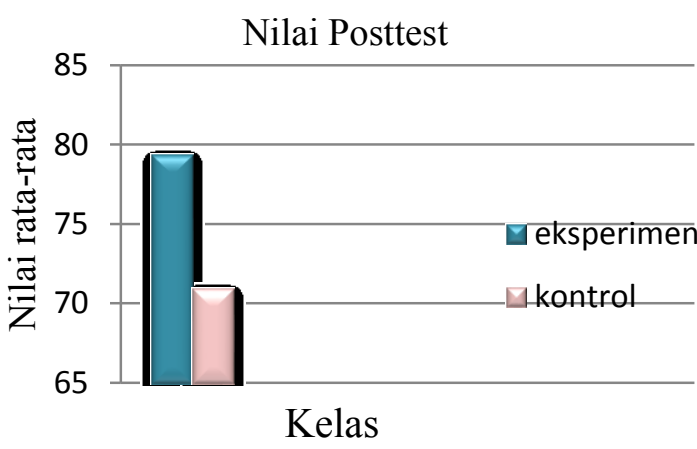

Gambar 6. Diagram perbandingan nilai ratarata posttest kelas kontrol dan eksperimen

Dari grafik di atas dapat dilihat bahwa nilai rata-rata posttest kelas eksperimen lebih tinggi dibandingkan nilai rata-rata kelas kontrol. Hal ini dikarenakan tingkat pemahaman siswa kelas eksperimen dalam memahami materi lebih tinggi dibandingkan kelas kontrol. Karena pada kelas eksperimen diterapkan pembelajaran saintific dengan model pembelajaran SAVI (Somatic Auditory Visualization Intelectually) dilengkapi media CD interaktif struktur atom yang dapat memaksimalkan belajar siswa dibandingkan kelas kontrol.

Selanjutnya dilakukan analisis data akhir (uji hipotesis) Analisa data dilakukan dengan menggunakan tes " $\mathrm{t}$ ". Namun penggunaan tes " $t$ " tersebut harus memenuhi dua syarat yaitu uji homogenitas dan normalitas. Uji normalitas berguna untuk membuktikan data dari sampel yang dimiliki berasal dari populasi berdistribusi normal. Data ini diperoleh dari nilai posttest diolah dengan menggunakan uji Chi Kuadrat. Hasil Uji normalitas terangkum dalam tabel berikut:

Tabel 5. Rangkuman Hasil Analisis Data Uji Normalitas

\begin{tabular}{|c|c|c|c|}
\hline Kelas & $\mathrm{X}_{2}$ & $\mathrm{X}_{2}$ & Kriteria \\
\hline & Hitung & Tabel & \\
\hline Eksperimen & 2,221 & 7,81 & Normal \\
\hline Kontrol & 3,153 & 7,81 & Normal \\
\hline
\end{tabular}

Uji normalitas berguna untuk membuktikan data dari sampel yang dimiliki berasal dari populasi berdistribusi normal. 
Setelah dilakukan uji normalitas maka dilakukan uji homognitas akhir untuk melihat varians-varians antara kelas kontrol dan eksperimen merupakan homogen. Hal ini dapat dilihat pada rangkuman tabel berikut:

Tabel 6. Rangkuman Hasil Analisis Data Uji Homogenitas Akhir

\begin{tabular}{lllll}
\hline Kelas & & varians & $\mathrm{F}$ & $\mathrm{F}$ \\
& $\mathrm{N}$ & & hitung & table \\
\hline Eksperimen & 34 & 186,01 & 1,35 & 1,82 \\
Kontrol & 37 & 251,16 & & \\
\hline
\end{tabular}

Berdasarkan uji homogenitas nilai posttest dari kelas eksperimen dan kelas kontrol, dari perhitungan yang diperoleh didapatkan $\mathrm{F}_{\text {hitung }}<\mathrm{F}_{\text {tabel }}$. yaitu $1,35<1,82$ maka dapat disimpulkan varians-varians kedua kelas tersebut adalah homogen.

Setelah dilakukan uji normalitas dan homogenitas, data hasil penelitian mempunyai data yang terdistribusi normal dan homogen. Karena $\mathrm{n}_{1} \neq \mathrm{n}_{2}$ dan varians homogen maka rumus test " $\mathrm{t}$ " yang digunakan dalam analisis data ini adalah test " $t$ " dengan polled varians. Hasil uji tes " $\mathrm{t}$ " terangkum dalam tabel berikut ini:

Tabel 7. Rangkuman Hasil Analisis Data Uji Hipotesis

\begin{tabular}{cccccc}
\hline Kelas & $\mathrm{N}$ & $\sum \mathrm{X}$ & $\overline{\mathrm{X}}$ & $\mathrm{T}_{\text {hitung }}$ & $\mathrm{T}_{\text {table }}$ \\
\hline $\begin{array}{c}\text { Eksperi } \\
\text { men }\end{array}$ & 34 & 1655 & 79,41 & 2,401 & 2,00 \\
Kontrol & 37 & 1525 & 70,95 & & \\
\hline
\end{tabular}

Berdasarkan data di atas dapat dilihat nilai $\mathrm{t}_{\text {hitung }}>\mathrm{t}_{\text {tabel }}$ disimpulkan bahwa $\mathrm{H}_{0}$ ditolak dan Ha diterima. Dengan kata lain Ada pengaruh penerapan model pembelajaran Somatic Auditory Visualization Intellectually (SAVI) menggunakan media CD Interaktif terhadap hasil belajar siswa kelas $\mathrm{X}$ pada materi struktur atom di SMK Negeri Pertanian Terpadu Pekanbaru Tahun Ajaran 2016/2017.

Berdasarkan analisis $\mathrm{Kp}$ atau koofisien pengaruh dari hasil posttest kelas eksperimen yang menggunakan model
Pembelajaran Somatic Auditory Visualization Intellectually (SAVI) dan kelas kontrol dengan pendekatan Saintific didapatkan pengaruh terhadap hasil belajar sebesar $7,7 \%$.

\section{SIMPULAN}

Berdasarkan analisis hasil penelitian dan pengujian hipotesis yang dilakukan terdapat pengaruh hasil belajar pada pokok bahasan struktur atom antara siswa yang belajar menggunakan pendekatan saintific dengan siswa yang diterapkan model pembelajaran Somatic Auditory Visualization Intellectually (SAVI) menggunakan media CD Interaktif Struktur Atom. Hasil analisis uji $t$ menunjukkan $t_{\text {hitung }}$ $>t_{\text {tabel }}$ dari hasil perhitungan diperoleh bahwa $t_{\text {hitung }}=2,401$ sedangkan nilai $t_{\text {tabel }}$ pada taraf signifikan $5 \%=2,00$. Dimana rata-rata dari hasil posttest kelas eksperimen didapatkan sebesar 79,41 dan kelas kontrol sebesar 70,95. Sehingga $\mathrm{H}_{0}$ ditolak dan $\mathrm{Ha}$ diterima. Pengaruh Penerapan model Pembelajaran Somatic Auditory Visualization Intellectually (SAVI) dengan menggunakan media CD interaktif struktur atom terhadap hasil belajar sebesar 7,7\%.

\section{REFERENSI}

Abdul Majid, Perencanaan Pembelajaran Mengembangkan Standar Kompetensi Guru, Bandung: PT Remaja Rosdakarya, 2011, pp. 45.

Anas Sudijono, Pengantar Evaluasi Pendidikan, Jakarta: Rajawali Press, 2009, pp. 164-165.

Dave Meier, "The Accelerated Learning Hand Book." Panduan Kreatif dan Efektif Merancang Program Pendidikan Penelitian, Bandung: Kaifa, 2002, pp. 92.

Defri Restian dan Sri Mantini Rahayu Sedyawati, "Pembelajaran Somatik Auditori Visual Intelektual (SAVI) Dengan Media Compact Disc Interaktif," Jurnal Inovasi Pendidikan Kimia, Vol 7, No 2 ISSN 1854-7108, pp. 1176, Apr. 2013. 
E. Kosasih, Strategi Belajar dan Pembelajaran Implementasi Kurikulum 2013, Bandung: Yrama Widya, 2014, pp. 101.

E. Mulyasa, Pengembangan dan Implementasi Kurikulum 2013, Bandung: PT Remaja Rosdakarya, 2014, pp. 9.

Istarani dan Muhammad Ridwan, 50 Tipe Pembelajaran Kooperatif, Medan: Media Persada, 2014, pp. 91.

Miftahul Huda, Model-Model Pengajaran dan Pembelajaran: Isu-Isu Metodis dan Paradigmatis, Yogyakarta: Pustaka Pelajar, 2013, pp. 91.

Muuhammad Afriawan, A. Binadjab, Latifahb. "Pengaruh Penerapan Pendekatan Savi Bervisi Sets Pada pencapaian Kompetensi Terkait Reaksi Redoks," Unnes Science Education Journal, Vol 2, USEJ 1 ISSN 22526617, pp. 58, Nov. 2012.

Nana Sudjana, Penilaian Hasil Proses Belajar Mengajar, Bandung: PT. Remaja Rosda Karya, 2009, pp. 135136.

Nana Sudjana. Dasar-Dasar Proses Belajar Mengajar. (Bandung: Sinar Baru Algensindo, 1995), hlm. 39.

Oemar Hamalik, Proses Belajar Mengajar, Jakarta: PT Bumi Aksara, 2010, pp. 20.

Purwanto, Statistika Untuk Penelitian, Yogyakarta: Pustaka Pelajar, 2011, pp. 180-181.

Ramayulis, Ilmu Pendidikan Islam, Jakarta: Kalam Mulia, 2002, pp. 28.

Riduwan, Dasar-Dasar Statistika, Bandung: Alfabeta, 2010, pp. 18.

Rusman, Model-model Pembelajaran, Bandung: Mulia Mandiri Press, 2010, pp. 373.

Slameto, Belajar dan Faktor-Faktor yang Mempengaruhinya, Jakarta: Rineka Cipta, 2010, pp. 97.

Sura Menda Ginting dan Hermansyah Amir. "Penerapan Model Pembelajaran Somatis Auditori Visual dan Intelektual (SAVI) Berbantuan Media Komputer
Untuk Meningkatkan Kualitas Pembelajaran Kimia Fisika II," Jurnal Exacta, Vol. X No. 1 ISSN 1412-3617, pp. 104, June. 2012. 
